\title{
The comparison of cultures, widal agglutination test and polymerase chain reaction as a diagnostic tool in typhoid fever
}

\author{
Research Article
}

\author{
Illker Devrim", Koray Ergünay², Ates Kara ${ }^{1}$, Hasan Tezer ${ }^{1}$,

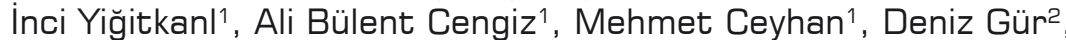 \\ Gülten Seçmeer ${ }^{1}$, Şemsettin Ustaçelebi ${ }^{2}$ \\ Hacettepe University, Faculty of Medicine, Department of Pediatrics, \\ Turkey, Ankara \\ ${ }^{2}$ Faculty of Medicine, Department of Microbiology and Clinical Microbiology \\ Hacettepe University, Turkey, Ankara
}

Received 1 April 2008; Accepted 13 June 2008

Abstract: Typhoid fever caused by Salmonella typhi, paratyphi A and B, is an important cause of morbidity and mortality in many developing countries. A rapid and sensitive method for the detection of $S$. typhi is essential for early diagnosis of typhoid fever and effective therapy. In this study 45 febrile patients who were suspected to have enteric fever were enrolled, and the results of blood cultures, widal agglutination tests and Polymerase Chain Reaction in these cases were evaluated. Group I consisted of 11 patients with diseases other than salmonella infections, group II represented 6 patients with positive cultures, and group III represented 28 patients with negative blood cultures negative but who were clinically suspected cases that had a medical history of using variable antimicrobial agents. Two positive PCR results were present; one of them was in culture positive group (16,6\%) and the other was in culture negative group $(3,5 \%)$. In our study widal agglutination tests and cultures were found not to be helpful in differential dignosis. Although PCR based detection of $S$. typhi is reported to be a sensitive and specific test for the diagnosis of enteric fever, in our study the benefit of this method in the diagnosis of especially patients who were treated with antimicrobial therapy was not clearly determined. Other methods to increase sensitiviy and specificity to levels such as those of real time PCR should be developed and large-scaled studies should be done in endemic and non-epidemic regions.

Keywords: Widal agglutination test • Polymerase chain reaction • Typhoid fever

(c) Versita Warsaw and Springer-Verlag Berlin Heidelberg.

\section{Introduction}

Typhoid fever caused by Salmonella typhi is an important cause of morbidity and mortality in many developing countries. Typhoid fever was estimated to have caused 21.6 million illness and 216500 deaths globally in 2000 [1]. A rapid and sensitive method for the detection of $S$. typhi is essential for early diagnosis of enteric fever and thus effective and rapid therapy.

Several different techniques are used for the diagnosis of typhoid fever. The gold standard for typhoid fever is isolation of $S$. typhi in the samples of patients including blood, bone marrow aspirates, stool, urine and rose spots. However, blood cultures fail to detect $10-70 \%$ of patients with typhoid fever with the different ratios changing due to the amount of blood sampled, phase of the disease, type of culture medium, length of incubation period and prompt antimicrobial usage $[2,3]$. A second disadvantage of the blood cultures is its requiring at least about 5 days for the isolation [4].

The most commonly used conventional method is the Widal agglutination test. Although its advantages include low cost and easy conductance, this test had limited diagnostic value due to moderate sensitivity and specificity and association with high false-positive and false-negative results [5]. Especially in endemic regions, widal tests were not easy to interpret since cross- 
reactions could be seen in other infectious diseases such as malaria and dengue [5]. Also, variable sensitivity and specificity results of the widal tests could be seen in different geographic regions, and different cut-off titers make the test unreliable [6]. The widal test would be also positive quite late in illness Other new tests such as the Tubex test, Typhidot tests and IgM dipstick tests are new techniques but more investigations to evaluate sensitivity and specificity are required [7].

Recently new molecular techniques have been developed and used in diagnosis of infectious diseases including salmonella infections. Polymerase chain reaction $(P C R)$ is a rapid and sensitive method that can amplify one copy of the target DNA of S. typhi.

In this study, we have evaluated the results of blood cultures, widal agglutination tests and the PCR technique from children with suspected typhoid fever.

\section{Material and Methods}

\subsection{Patients}

Blood samples were taken from the patients with suspected enteric fever who were admitted to Hacettepe University Ihsan Doğramacı Children's Hospital between 1 April 2006 and 1 April 2007 after informed consent was obtained. All the patients had fever for at least 72 hours and at least one of the following complaints, including diarrhea \pm vomiting, constipation, abdominal pain, central nervous system complaints and clinical findings including fever, headache, confusion, hepatomegaly, splenomegaly and abdominal discomfort.

Patients were investigated for other etiologic infectious and inflammatory diseases. Patients were regrouped into three groups (Table 1) according to the etiology of fever. Blood samples for cultures, widal tests, PCR urine and stool cultures were obtained from all patients and bone marrow cultures were also obtained from the indicated cases. Laboratory tests including serum hemoglobin levels, white blood cell count, platelet count, peripheral smear, erythrocyte sedimentation rate, serum C-reactive protein, aspartate amino transferase, alanine amino transferase, lactate dehydrogenase levels, protrombin time, activated partial thromboplastin time were applied to patients. For diagnostic purposes bone marrow aspirations, fibrinogen levels, ferritin levels, serum triglyceride levels, total cholesterol levels, abdominal ultrasonography, echocardiograpy were done in indicated cases. The following serological tests were applied, including Ebstein-barr virus, Clamidia pneumonia and mycoplasma pneumonia, cytomegalovirus, herpes simplex virus and brucella, as well as parvovirus B19 DNA if indicated.

\subsection{Sampling}

Approximately $10 \mathrm{ml}$ of blood specimens was collected from the patients, and $5 \mathrm{ml}$ of the specimen was put into a bottle containing $15 \mathrm{ml}$ bile broth for blood culture. 1 $\mathrm{ml}$ was separated for extracting DNA into a tube and rest was separated for Widal agglutination tests.

\subsection{PCR}

The total DNA from serum samples was purified using the standard phenol/chloroform extraction and ethanol precipitation method as described elsewhere and recommended previously (Sambrook, Cocolin). Twenty $\mathrm{pg} / \mathrm{ml}$ of each of the primers Salm-3 (5'GCTGCGCGCGAACGGCGAAG-3') and Salm-4 (5'-TCCCGGCAGAGTTCCCATT-3') were used in a $50 \mu \mathrm{PCR}$ mix containing $10 \mathrm{mM}$ Tris- $\mathrm{HCl}$ (ph:8.3), $50 \mathrm{mM} \mathrm{KCl}, 1.5 \mathrm{mM} \mathrm{MgCl}_{2}$ in PCR Reaction Buffer (Roche Diagnostics, Germany), 0.25 mM dNTPs (PCR Nucleotide Mix, Roche Diagnostics, Germany) and 2,5 U Taq DNA polymerase (Roche Diagnostics, Germany) (Cocolin). Thermocycling was performed in a GeneAmp PCR System 9700 (Applied Biosystems, USA) using the program that consisted of 2 minutes of denaturation at $95^{\circ} \mathrm{C}, 35$ cycles of $95^{\circ} \mathrm{C}$ for 90 seconds, $58^{\circ} \mathrm{C}$ for 80 seconds and $72^{\circ} \mathrm{C}$ for 2 minutes, followed by a final extension at $72^{\circ} \mathrm{C}$ for 7 minutes as described before (Cocolin). Expected amplicons of 389 basepairs were visualized in $2 \%$ agarose gel after electrophoresis and ethidium bromide staining under ultraviolet light. A strain of Salmonella group $D$, isolated and identified by biochemical tests were used as a positive control after cultivation on SS and McConkey agar and purification by High Pure PCR Template Kit ${ }^{\circledR}$ (Roche Diagnostics, Germany). Preparation of PCR mixes and electrophoresis were performed in separate laboratories to prevent cross-contamination.

\subsection{Widal agglutination tests}

Commercially prepared coloured antigen was used as $S$. typhi $\mathrm{O}$ and $\mathrm{H}$ antigens. The patients' sera were tested for agglutinins against each of the different Salmonella suspensions and the widal agglutination test against Salmonella typhi $\mathrm{O}$ antigen titer of 1:160 in the single sera or more was considered positive. 
Table 1. Signs and symptoms of cases in groups I, II and III.

\begin{tabular}{|c|c|c|c|c|c|}
\hline \multirow[t]{2}{*}{ Sign and symptoms } & \multirow[b]{2}{*}{ Group I } & \multirow[b]{2}{*}{ Group II } & \multirow[b]{2}{*}{ Group III } & \multirow[b]{2}{*}{ Total } & \multirow[b]{2}{*}{ Percentage } \\
\hline & & & & & \\
\hline Fever & 11 & 6 & 28 & 45 & 100 \\
\hline Diarrhea \pm vomiting & 6 & 4 & 16 & 28 & 62,2 \\
\hline Constipation & 3 & 2 & 9 & 14 & 31,1 \\
\hline $\begin{array}{l}\text { Abdominal pain } \\
\text { (abdominal discomfort) }\end{array}$ & 5 & 5 & 14 & 24 & 53,3 \\
\hline $\begin{array}{l}\text { Central nervous system } \\
\text { findings (including altered } \\
\text { consciousness, meningeal } \\
\text { signs, encephalopathy) }\end{array}$ & 1 & 1 & 3 & 5 & 11,1 \\
\hline Arthritis & 1 & 1 & 2 & 4 & 8,8 \\
\hline Rash & 1 & 2 & 3 & 6 & 13,3 \\
\hline Bradycardia & - & - & 1 & 1 & 2,2 \\
\hline Rose spots & - & - & - & - & \\
\hline Splenomegaly & 1 & - & - & 1 & 2,2 \\
\hline Hepatomegaly & 1 & - & - & 1 & 2,2 \\
\hline Hepatosplenomegaly & 3 & 2 & 2 & 7 & 15,5 \\
\hline
\end{tabular}

\section{Results}

\subsection{Characteristics of patients}

There were 45 patients with prolonged fever and the associated clinical features listed above, including 26 boys and 19 girls with ages ranging from 1 month of age to 17 years (mean $6.45 \pm 4.7$ years, median age 5.00 ). Seventy one percent of the patients had diarrhea \pm vomiting, $64,4 \%$ had abdominal discomfort, $31,1 \%$ had constipation, $4,4 \%$ had central nervous system findings such as confusion (Table 1 ).

Overall, the average serum hemoglobin level of the patients was $11,5 \pm 1,6 \mathrm{~g} / \mathrm{dl}$ (median 11,7 g/dl), the average white blood cell count was $10440 \pm$ $3789 / \mathrm{mm}^{3}$ (median $10700 / \mathrm{mm}^{3}$ ), the average platelet count was $368866 \pm 153000 / \mathrm{mm}^{3}$, the aspartate amino transferase level was 50,4 \pm 95,6 U/L (median $30 \mathrm{U} / \mathrm{L}$ ) and the alanine amino transferase level was $34,05 \pm$ $68,89 \mathrm{U} / \mathrm{L}$ (median $20 \mathrm{U} / \mathrm{L}$ ).

Group I consisted of 11 patients whose fever was found to be due to diseases other than salmonella infections, including Kawasaki disease, hemophagocytic lymphohistiocytosis, sepsis due to $E$. coli, osteomyelitis, systemic juvenile arthritis, cholangitis and meningitis. Group II represented 6 patients with positive cultures in which group D salmonella serotype was isolated. Group III represented 28 blood culture negative but clinically suspected cases, in which all patients in this group had a medical history of using variable antimicrobial agents for a two week period.
In group II salmonella group D was isolated in 6 patients, while in groups I and III there was no isolation of salmonella species in the cultures (Table 2).

\subsection{Interpretation of Widal-agglutination tests} In group I 4 patients $(36,3 \%)$ had positive Widal agglutination tests. In the culture positive cases 4 patients $(66,7 \%)$ had positive Widal agglutination test, whereas in the culture negative group 11 patients $(39,25 \%)$ had positive widal agglutination test results (Table 2).

\subsection{Results of PCR assay}

Two positive PCR results were obtained; one of them was in the culture positive group (16,6\%) and the other was in the culture negative group $(3,5 \%)$. The positive result in group II belonged to a patient for whom bone marrow and blood cultures were both positive for $S$. typhi (Table 2).

\section{Discussion}

Infections due to salmonella infections are an important global health problem. A rapid and sensitive method for detection of $S$. typhi is important not only for effective therapy and diagnosis, but also for prevention of complications and dissemination of outbreaks. Since the clinical features of enteric fever were non-specific and several diseases were considered in differential diagnosis, a new rapid and sensitive method for differential diagnosis of enteric fever was required. 
Table 2. Comparison of PCR and blood culture positive for detection of S. typhi in groups I, II and III.

\begin{tabular}{l|llll}
\hline Group & Number of cases & $\begin{array}{l}\text { Positive widal agglutination } \\
\text { test (\%) }\end{array}$ & $\begin{array}{l}\text { Blood cultures positive for } \\
\text { S. typhi (\%) }\end{array}$ & $\begin{array}{l}\text { Amplicons of desirable size } \\
\text { present in PCR for S. typhi (\%) }\end{array}$ \\
\hline \hline I & 11 & $4(36,3 \%)$ & - & - \\
II & 6 & $4(66,7 \%)$ & 1 & 1 \\
-S. typhi & 1 & 1 & $1(100 \%)$ & $1(100 \%)$ \\
-non-typhoidal & 5 & 3 & - & - \\
III & 28 & $11(39,25 \%)$ & - & $1(3,5 \%)$ \\
\hline
\end{tabular}

Diagnosis of typhoid fever is based on primarly on isolation of bacteria in clinical samples especially from blood cultures, bone marrow and sterile body fluids. In our study the ratio of culture positive to negative cases were low, and the probable factors were prior administration of antibiotics and collection of samples 7-10 days after the onset which was associated with second bacteremic phase characterized by low numbers of bacteria in circulation $[8,9]$. The patients in the culture positive group (group III) had a history of prior antibiotic administration strongly suggesting the negative effect of prior antibiotic usage. Blood cultures were reported to be negative in $30-55 \%$ of cases and dependent factors include the amount of bacteria in circulation, the sampling procedures and volume of sampled blood cultures [1].

The second most commonly used and preferred diagnostic tool for typhoid fever is the widal agglutination test, which had limitations such as low sensitivity and limited benefits when one serum sample was obtained [6]. Although in the culture positive group (group II), $66,7 \%$ of the patients had positive widal agglutination test results, no significant difference was found between these three groups.

In our study, two positive PCR results were present, one in group II and one in group III; no positive PCR result from the samples taken in group I was present. The oligonucleotide primers used in the study had been described for detection of salmonella species, especially for S. typhi infections targeting the invA gene [10]. In our study when further serotyping of the isolated group D salmonella species, one $S$. typhi serotype was recognized in which the PCR test was also positive. The invA gene was reported to be essential for invasion to the epithelial cells, which means when expressed, a higher chance for bacteremia was observed [10] but the specific 389 bp PCR amplicon was reported to be not specific for $S$. typhi. The positive case for desired PCR amplicon was in group II and limited to the case with positive blood cultures for $S$. typhi serotype; this PCR method could be more specific to $S$. typhi than reported before. In our study specificity of PCR methods were found to be higher than sensitivity since it was all negative in group I. Our study had a limitation because we did not use the DNA hybridization method that could increase the sensitivity of PCR. Although a study using the same PCR method reported before that they were not able to find positive results in clinical samples (in that report the 389 bp PCR amplicon was shown in samples from artificially inoculated rats) [10], we were able to detect bacteremic patients with this method in groups II and III. The low ratio of PCR positive cases in the culture negative group could be due to the presence of inhibitor material such as previously administered antibiotics. Additional methods to increase the sensitiviy of PCR were required. Antibiotics were widely used among typhoid fever patients before diagnosis especially in non-endemic areas, since it mimics a wide spectrum of diseases such as sepsis due to other gram negative bacteria, Kawasaki disease, etc.

In conclusion, although PCR based detection of S. typhi is reported to be a sensitive and specific test for diagnosis of typhoid fever, studies concerning the benefit of PCR in the diagnosis of patients who were treated with antimicrobial therapy are not present. In our opinion, PCR based diagnosis of $S$. typhi is a sensitive and specific test as reported before [4], but other methods to increase sensitiviy and specificity such as real time PCR should be performed and large-scaled studies should be done in endemic and non-epidemic regions since multicenteral studies are lacking in the literature. 


\section{References}

[1] Crump JA, Luby SP, Mintz ED. The global burden of typhoid fever. Bull World Health Organ 2004; 82: 346-53.

[2] Gasem MH,. Dolmans WM, Isbandrio BB et al. Culture of Salmonella typhi and Salmonella paratyphi from blood and bone marrow in suspected typhoid fever. Trop Geogr Med 1995; 47: 164-67.

[3] Wain J, Diep TS, Ho VA, et al. Quantitation of bacteria in blood of typhoid fever patients and relationship between counts and clinical features, transmissibility, and antibiotic resistance. J Clin Microbiol 1998; 36: 1683-87.

[4] Kumar A., Arora V., Bashampoo A et al. Detection of Salmonella typhi by polymerase chain reaction: Implications in diagnosis of typhoid fever. Infection, Genetics and Evolution 2 (2002) 107-110.

[5] Olopoenia LA, King AL. Widal agglutination test - 100 years later: still plagued by controversy. Postgrad Med J 2000;76:80-84.

[6] Tupasi TE, Lucas-Aquino R, Mendoza MT et al. Clinical Application of the Widal Test. Phil J Microbiol Infect Dis 1991; 20(1):23-26.
[7] World Health Organization. Background document: The diagnosis, treatment and prevention of typhoid fever. WHO/V \& B / 2007; 03: 1-38.

[8] Gilman, R.H., Terminel, M., Levine, M.M. et al. Relative efficacy of blood, urine, rectal swab, bonemarrow, and rose-spot cultures for recovery of Salmonella typhi in typhoid fever. Lancet 1975; 1 1211-1213.

[9] Hoffman, S.L., Punjabi, N.H., Rockhill, R.C. et al. Duodenal string capsule culture compared with bone-marrow, blood and rectal cultures for diagnosis typhoid and a paratyhphoid fever. J. Infect. Dis. 1984:149: 157-161.

[10] Cocolin L., Manzano M., Astori G et al. A highly sensitive and fast nonradioactive method for the detection of polymerase chain reaction products from Salmonella serovars, such as Salmonella Typhi, in blood specimens. FEMS Immunol and MedicMicrobiol 1998; 22: 233-239. 